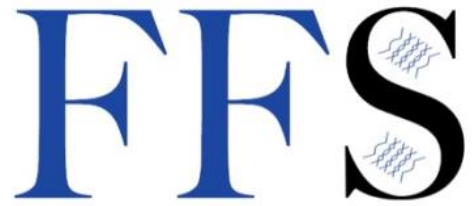

Functional Food Science

\title{
Pycnogenol - extract from French maritime pine bark (Pinus pinaster), as an effective antioxidant against superoxide radical
}

\author{
Beata Cizmarova ${ }^{1}$, Anna Birkova ${ }^{1,}{ }^{*}$, Beata Hubkova $^{1}$ and Beata Bolerazska ${ }^{2}$ \\ ${ }^{1}$ Department of Medical and Clinical Biochemistry, Faculty of Medicine, Pavol Jozef Safarik University in Kosice, Tr. \\ SNP 1, Kosice, Slovakia; ${ }^{2} 1$ st Department of Stomatology, Faculty of Medicine, Pavol Jozef Safarik University in Kosice, \\ Tr. SNP 1, Kosice, Slovakia.
}

*Corresponding author: Anna Birkova, MD, PhD, Department of Medical and Clinical Biochemistry, Faculty of Medicine, Pavol Jozef Safarik University in Kosice, Tr. SNP 1, Kosice, Slovakia

Submission Date: June $8^{\text {th }}$, 2021; Acceptance Date: August 24 ${ }^{\text {th }}, 2021$; Publication Date: August $31^{\text {st }}, 2021$

Please cite this as: Cizmarova B., Birkova A., Hubkova B., Bolerazska B. Pycnogenol - extract from French maritime pine bark (Pinus pinaster), as an effective antioxidant against superoxide radical. Functional Food Science 2021. 1(8): 14-22. DOI: https://www.doi.org/10.31989/ffs.v1i8.816

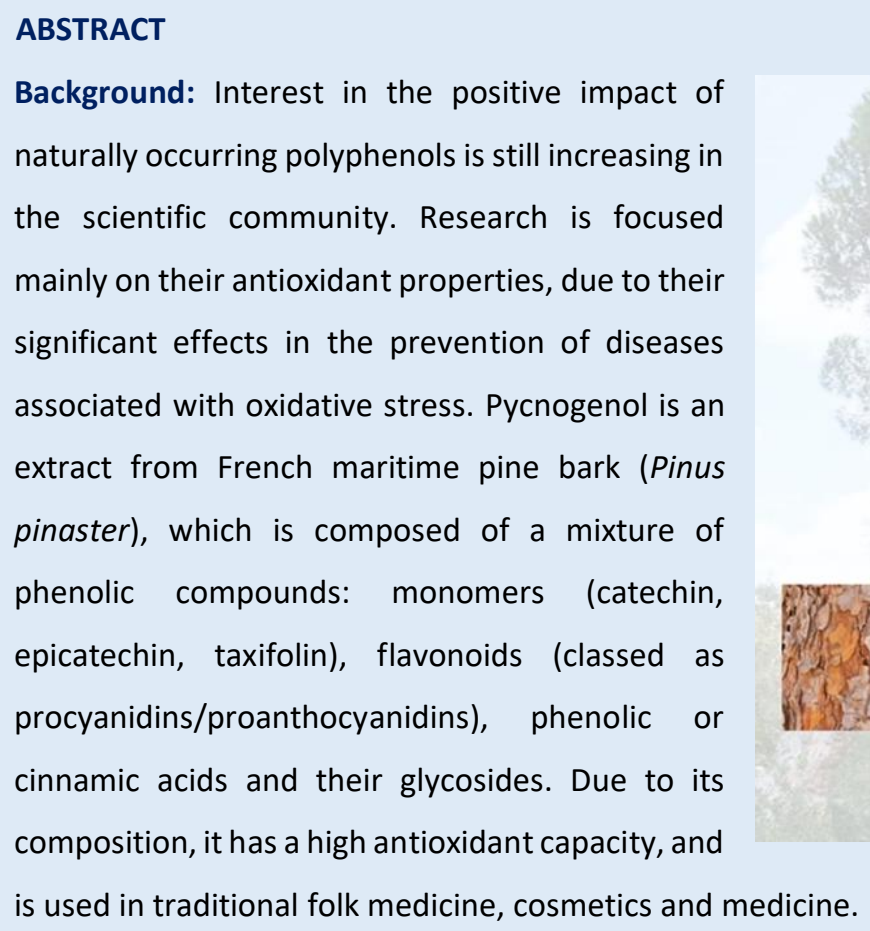


Purpose of the study: The aim is to study the antioxidant properties of pycnogenol in order to obtain experimental information on the antioxidant effect of pycnogenol in terms of concentration dependence and $\mathrm{pH}$ conditions.

Methods: In our study, we used a methionine-riboflavin superoxide generator, and focused on determining the antioxidant capacity of Pycnogenol against the superoxide radical in different pH values (range 6.5 - 8) using the spectroscopic method.

Results: Our results showed that the antioxidant properties increased with a higher concentration of the tested compound in the tested $\mathrm{pH}$ range. Amongst all tested $\mathrm{pH}$ values, the most appropriate for pycnogenol antioxidant capacity is slightly basic $\mathrm{pH}(\mathrm{pH} 8)$.

Conclusion: Information on the antioxidant and prooxidant properties of naturally occurring compounds is very important for understanding their activity and their proper use in prevention, disease treatment, and detection of pathological processes. The antioxidant activity of pycnogenol depends on the structure and concentration of antioxidants; it only slightly changes at different $\mathrm{pH}$ values. Increasing concentration of pycnogenol enhances its antioxidant properties.

Keywords: Pycnogenol, reactive oxygen species, spectrophotometry, pH dependency

CFFC 2021. This is an Open Access article distributed under the terms of the Creative Commons Attribution 4.0 License (http://creativecommons.org/licenses/by/4.0)

\section{INTRODUCTION}

Recently, there has been a huge and still increasing amount of evidence for the effects of naturally occurring compounds isolated from plants. These compounds are mostly polyphenols. Emphasis is placed primarily on their properties as antioxidants and also because of their significant effects in the prevention of various diseases associated with oxidative stress (defined as the imbalance between oxidants and antioxidants in the body) formed in organisms. One of the most common diseases associated with oxidative stress worldwide is malignancy, which is one of the reasons why an important area of human health research focuses on the identification, development and effects of phenolic compounds and plant extracts rich in polyphenols [1].
Phenolic compounds have long been considered potent strong antioxidants which act in vitro. The relationship between their structure and antioxidant activity and dosage is very important. In some studies, they have been shown to be more effective antioxidants than vitamin $E$, vitamin $C$ and carotenoids [2]. There is ample evidence of a relationship between fruit and vegetable intake and the risk of civilization diseases. A balanced diet rich in fruits and vegetables with high content of natural antioxidants has been shown to reduce the risk of chronic diseases such as malignancy, diabetes mellitus, Alzheimer's disease, cardiovascular diseases [3-4].

Instead of the above-mentioned beneficial antioxidant properties of flavonoids, they may in certain circumstances promote the oxidation of other 
molecules, thereby acting as prooxidants [2] and initiating oxidation stress. The antioxidant/prooxidant activity of phenols is dependent on many factors, such as chelating properties, structure, solubility properties, and $\mathrm{pH}$. In studies by Gray (1994), and Gaspar et al. (1994) [5-6], the prooxidant properties of phenols and the induction of DNA damage by polyphenols in varying $\mathrm{pH}$ were observed. The structure of the mentioned compounds is also important. Flavonoids are generally composed of aromatic rings with one or more hydroxyl groups attached, thereby potentially being able to quench free radicals. In many studies, the relationship of antioxidant activity to the number as well as the position of hydroxyl groups in the structure is reported; higher antioxidant efficiency has been demonstrated when the hydroxyl functional groups are situated on adjacent carbon atoms [7-9].
In our study, we discuss the antioxidant activity of pycnogenol (PYC) against the superoxide radical in relation to different $\mathrm{pH}$ values (range 6.5 - 8), determined by the spectroscopic method. PYC is an extract from French maritime pine bark (Pinus pinaster) which is produced by a validated extraction procedure. The chemical composition of PYC is still not fully understood, but it is clear that PYC is mostly composed of a mixture of phenolic compounds (Table $1)$, which includes monomers (catechin, epicatechin, taxifolin), flavonoids (classified as procyanidins/proanthocyanidins), phenolic or cinnamic acids and their glycosides [10-11]. Due to its composition, it has a high antioxidant capacity, and is used in traditional folk medicine. The use of pine bark extract in nutrition, cosmetics and medicine has also been previously described [12-13].

Table 1. The chemical composition of pycnogenol $[12,14]$.

\begin{tabular}{l|l|l}
\hline Phenolic compounds & Procyanidins $(70-85 \%)$ & $\begin{array}{l}\text { Polymers composed of: } \\
\text { Catechin Epicatechin }\end{array}$ \\
\hline Flavanol monomers & $\begin{array}{l}\text { Catechin } \\
\text { Epicatechin } \\
\text { Taxifolin }\end{array}$ \\
\hline Benzoic acids & $\begin{array}{l}\text { p-Hydroxybenzoic acid } \\
\text { Protocatechuic acid }\end{array}$ \\
\hline & Vanillic acid \\
\hline Cinnamic acids & Gallic acid \\
\hline Inorganic ions & $\begin{array}{l}\text { p-Coumaric acid } \\
\text { Caffeic acid }\end{array}$ \\
\hline calcium, potassium, iron, manganese, zinc, copper, selenium (traces)
\end{tabular}

In many countries, PYC is available as an overthe-counter product in the form of tablets or capsules with various dosing. Its metabolization and degradation in the human body is also important. PYC is composed of multiple constituents, as mentioned above. After ingestion, the phenolic compounds are cleaved in the colon by microbial enzymes to form smaller and more bioavailable molecules. These smaller molecules could be absorbed by the colon into the bloodstream and thus transported to tissues and organs [14]. Other components, such as ferulic acid and taxifolin, are rapidly absorbed and subsequently excreted in the form of sulphates or glucuronides. However, procyanidins are absorbed 
slowly, metabolized to valerolactones, and excreted as glucuronides [15].

According to the Scientific and Clinical Monograph for Pycnogenol published by the American Botanical Council, PYC was considered safe by FDA experts and was designated "generally recognized as safe" (GRAS). The safety of PYC was observed in 91 human clinical studies with 6849 participants. Adverse events of PYC reported with frequency of $2.4 \%$ were unrelated to the dose and to the duration of supplementation. Reported adverse events include headache, nausea, dizziness, and it is recommended that PYC to be taken with food due to frequent gastrointestinal problems [16].

Thanks to its composition, PYC has many beneficial effects on human health [17]. PYC acts as antioxidant, protecting cells against oxidative stress by different mechanisms. PYC is a free radical scavenger, increasing the synthesis of antioxidant enzymes, and protecting endogenous antioxidants such as vitamin $C$, vitamin $E$, and glutathione from oxidative damage $[15,18]$. The synergistic effect of PYC components is associated with cardiovascular benefits, antithrombotic effects, reduced cancer risk, as well as the prevention of degenerative diseases, premature aging, and neurotoxicity. It is a promising additive in the treatment of ADHD protects against lipid peroxidation, and improves conditions in diabetes, asthma, osteoarthritis. More information on the positive and beneficial biological activity of PYC extract led to its use as a worldwide dietary supplement $[14,17,19-20]$.

Pycnogenol is a potent over-the-counter dietary supplement, but its interactions with other food components are not well described yet. The aim of our study was to prove the antioxidant properties of pycnogenol in order to obtain basic information on the antioxidant effect of pycnogenol in terms of concentration and $\mathrm{pH}$ conditions needed to achieve the desired positive effect.

\section{METHODS}

Materials: All chemicals used in the experiments were of p.a. purity. L-methionine and nitrotetrazolium blue (NTB) were purchased from MERCK (Merk Schuchardt OHG, Hohenbrunn, Germany). The EDTA, $\mathrm{K}_{2} \mathrm{HPO}_{4}$ and $\mathrm{KH}_{2} \mathrm{PO}_{4}$ were purchased from ITES (ITES, Vranov nad Topl'ou, Slovakia). We used $50 \mathrm{mM}$ phosphate buffer $\left(\mathrm{KH}_{2} \mathrm{PO}_{4}\right.$ and $\mathrm{K}_{2} \mathrm{HPO}_{4}$ ) with different $\mathrm{pH}$ values $(6.5,7.0,7.4$, 7.6, 8.0), 13 mM L-methionine, 0.1 mM EDTA, 0.2 mM riboflavin, 5 mM NTB.

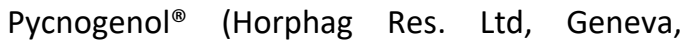
Switzerland) is an extract from the French pine (Pinus pinaster) bark. This extract is standardized to contain 70-85\% procyanidins.

In our study, methionine-riboflavin superoxide generator was used; reaction mixture contained 300 $\mu \mathrm{l}$ of $0.2 \mathrm{mM}$ riboflavin, $30 \mu \mathrm{l}$ of $5 \mathrm{mM} \mathrm{NTB}, 8.7 \mathrm{ml}$ of $50 \mathrm{mM}$ phosphate buffer at pH 6.5, 7.0, 7.4, 7.6 and 8.0, EDTA and L-methionine. The tested compound was added at concentrations ranging from $5 \mu \mathrm{g} / \mathrm{ml}$ to $50 \mu \mathrm{g} / \mathrm{ml}$. Riboflavin was added last. The reaction was initiated by placing the vessels under an $\mathrm{Hg}$ lamp. Illumination was performed for 20 minutes. Interfering trace amounts of metal ions were removed by the EDTA added in excess. The percentage of inhibition was calculated from the absorbance at wavelengths of 450 and $560 \mathrm{~nm}$ using the following formula:

$$
\begin{gathered}
\% \text { of inhibition }=\left[A_{0}(\text { time })-A_{x}(\text { time }) / A_{0}\right. \\
(\text { time })] \times 100,
\end{gathered}
$$

where $A_{0}$ is the absorbance of the composition without antioxidant, and $A_{x}$ is absorbance of composition with antioxidant, over time. 
The antioxidant properties of PYC were measured by a test reaction according to Beauchamp and Fridovich (1971) [21]. Riboflavin was reduced by L-methionine under aerobic conditions after UV illumination. The reduced form of riboflavin reacted with oxygen and formed a peroxide derivative, which was decomposed to superoxide radical anion. The superoxide ions were reduced by NTB compound. The original yellow color was oxidized during the reaction and changed to blue. The intensity of the blue color reduction was determined by spectrophotometry at wavelengths $450 \mathrm{~nm}$ and $560 \mathrm{~nm}$. The presence of any antioxidant (which captures the superoxide radical ion) inhibited photo-oxidation of NTB, and the studied sample was then decolorized from blue to yellow.
Statistical analysis: Data was analyzed using Microsoft Excel. Pearson correlation was performed to prove the significance between the concentration of PYC and the percentage of inhibition at different $\mathrm{pH}$.

\section{RESULTS AND DISCUSSION}

The absorbance of the reagent solution was measured at $450 \mathrm{~nm}$ and $560 \mathrm{~nm}$ after 20 minutes of illumination (Fig. 1, Fig. 2). The concentration of PYC ranged from 5 to $50 \mu \mathrm{g} / \mathrm{ml}$.

In our work, we tested the antioxidant capacity of PYC in reaction with superoxide radicals generated by the methionine-riboflavin generator at different $\mathrm{pH}$ levels. PYC is effective in the superoxide radical scavenging process at the tested $\mathrm{pH}$ values. The activity was shown to be the best for PYC at $\mathrm{pH} 8$ (Figure 1).

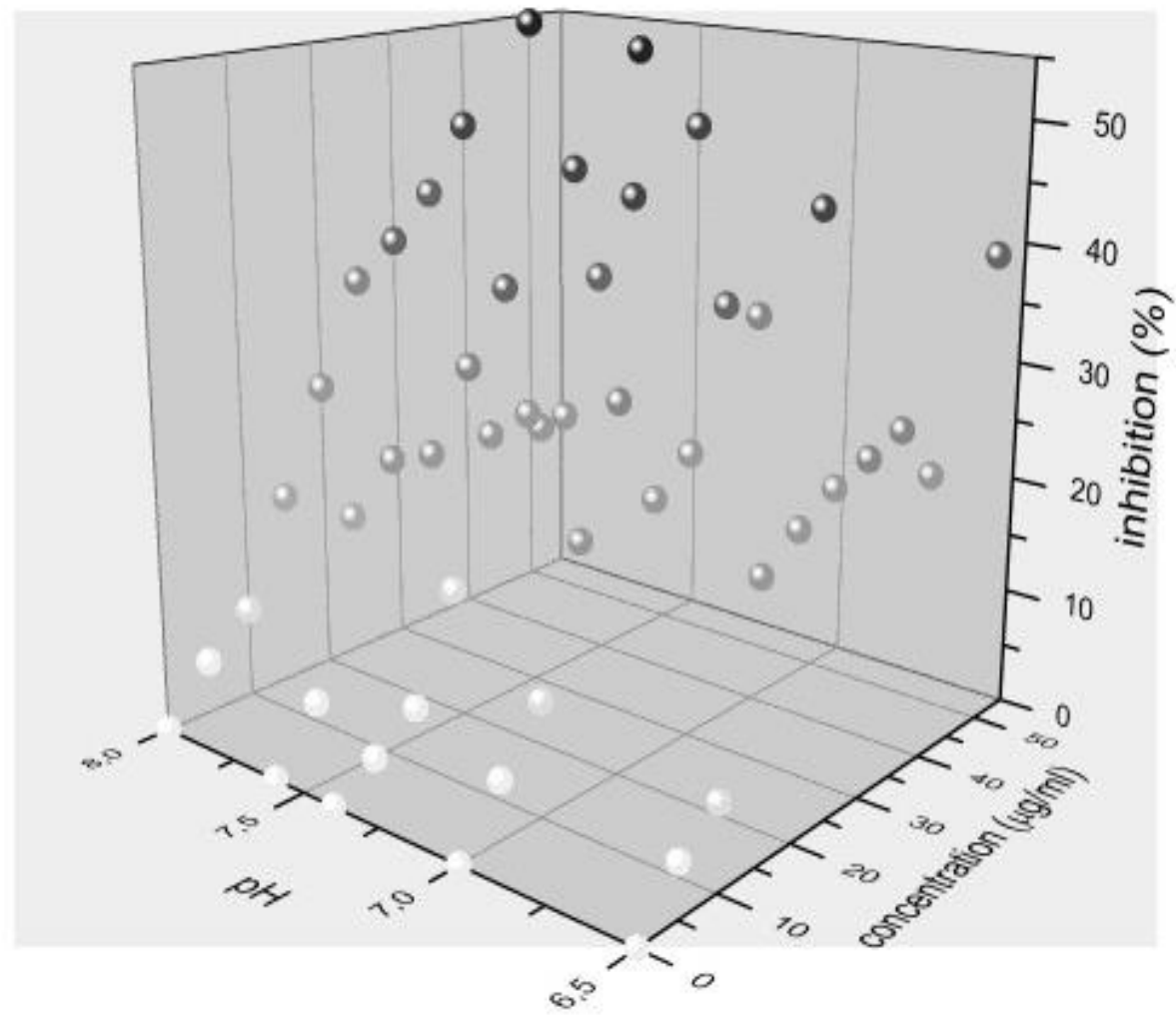

Figure 1. Antioxidant properties of pycnogenol against superoxide radical at different $\mathrm{pH}$ values. Dots represent single measurements, total amount of measurements $\mathrm{N}=45$. 
Table 2. Pearson's correlation and significance between the concentration of PYC and the percentage of inhibition at different $\mathrm{pH}$ values.

\begin{tabular}{|c|c|c|c|c|c|}
\hline Pearson's $r$ & pH 6.5 & pH 7.0 & pH 7.4 & pH 7.6 & pH 8.0 \\
\hline c (pycnogenol) $\mu \mathrm{g} / \mathrm{ml}$ & 0.876 & 0.912 & 0.974 & 0.893 & 0.986 \\
& $p=0.002$ & $p=0.0006$ & $p=0.000009$ & $p=0.001$ & $p=0.000001$ \\
\hline
\end{tabular}

PYC showed better antioxidant properties at concentrations above $30 \mu \mathrm{g} / \mathrm{ml}$. Based on our results, there is a strong correlation between antioxidant concentration and the percentage of inhibition at a $\mathrm{pH}$ ranging from 6.5 to 8 (Table 2).

Free radicals are generally defined as atoms or molecules that contain one or more unpaired electrons that allow them to oxidize other substances and cause oxidative stress. Superoxide $\left(\mathrm{O}^{2 \bullet-}\right)$ belongs to a group of reactive oxygen species (ROS) that are produced in the normal metabolic pathways of cells in the human body. The main source of superoxide production in vivo is the activity of the electron transport chain in mitochondria due to the escape of electrons passing through the chain [22]. Antioxidants, which are classified as enzymatic and non-enzymatic, serve as a defense system against the activity of free radicals. Some antioxidants are produced during normal metabolism (e.g. uric acid, glutathione), while others are ingested through the diet. Exogenous antioxidants, including polyphenols and their derivatives, are well described in the scientific literature [23]. The number and position of hydroxyl groups in the molecule determine their antioxidant activity. Rice-Evans et al. (1996) reported in their study that the electron-withdrawing properties of the carboxyl group in benzoic acids have a negative effect on the $\mathrm{H}$-donation of hydroxybenzoic acid derivatives [24]. PYC contains aromatic rings with one or more hydroxyl groups in their structure, which is promising for their main antioxidant role, and are therefore potentially able to quench free radicals by forming resonantly stabilized phenoxyl radicals.

In our study, we tested PYC (a mixture of flavonoids) in the $\mathrm{pH}$ range of $6.5-8$ (Figure 1 ). Pycnogenol was more effective at $\mathrm{pH}$ 8. However, its antioxidant activity changed only slightly at different $\mathrm{pH}$ levels. The behavior of PYC at the selected $\mathrm{pH}$ levels showed similarities. According to our results, the antioxidant properties increased with a higher concentration of PYC within the tested $\mathrm{pH}$ range.

PYC belongs to the polyphenols; it is generally known that the antioxidant activity of these widespread compounds depends on the number and position of hydroxyl and carboxyl groups in the molecule. Ortho-substituent derivatives may act as $\mathrm{H}$ bond acceptors; however, other functional groups such as methoxy- and hydroxy-groups, which are highly distributed in the structure of natural phenols, have opposite effects on the antioxidant properties [4]. Another very important factor of antioxidant activity is the duration of the action of these compounds [25]. There is also evidence of prooxidant activity of polyphenolic compounds under certain conditions, which could explain the in vivo toxicity of some polyphenols [26]. Prooxidizing activity cannot be considered exclusively harmful, as the prooxidizing effect can be useful and beneficial. For example, induction of moderate oxidative stress increases levels of antioxidant and biotransformation enzymes and, as a result, may induce overall cell protection 
[27]. There is insufficient information on the anti- and prooxidant properties of the compounds in vivo; this topic is still not sufficiently understood nor described and clearly requires further study. One factor may be the appropriate dosage of the compounds used. The test compound ranged from 0 to $50 \mu \mathrm{g} / \mathrm{ml}$. The prooxidizing properties of the test compound have not been demonstrated in this range. Increasing the concentration of PYC increases its antioxidant properties, and if the concentration used is higher than $30 \mu \mathrm{g} / \mathrm{ml}$, the antioxidant properties of the test compound were better. This study may contribute to the knowledge of the effects of pycnogenol, as supplements containing French maritime pine bark extract may differ significantly in terms of active substance content [28-29].

\section{CONCLUSIONS}

There is a lot of evidence illustrating the desirable effects of pycnogenol on the human body, but there are also studies pointing to its adverse effects. In order to avoid the undesirable adverse effects of pycnogenol administration, it is very important to know the suitable dosage of the antioxidant and its metabolisation in the body. Our results showed that pycnogenol is a potent antioxidant against superoxide radicals. Increase in pycnogenol concentration enhances its antioxidant properties. Subsequently, its structure- and concentration-dependent antioxidant activity changes only slightly at different $\mathrm{pH}$ levels (range 6.5 - 8).

Information on the antioxidant and prooxidant properties of naturally occurring compounds is very important in understanding their activity and their proper use in the prevention and treatment of diseases.
List of Abbreviations: ADHD: Attention Deficit Hyperactivity Disorder, EDTA: Ethylenediaminetetraacetic acid, FDA: United States Food and Drugs Administration, GRAS: generally recognized as safe, $\mu \mathrm{g} / \mathrm{ml}$ : microgram/milliliter, $\mathrm{nm}$ : nanometer, NTB: nitrotetrazolium blue, PYC: pycnogenol, ROS: reactive oxygen species

Conflict of interest: The authors have no conflicts of interest to declare.

Author's contributions: *Beáta Čižmárová performed the experimental research, **Anna Birková performed analytical calculation and contributed to interpretation of results, Beáta Čižmárová, Anna Birková and ***Beáta Hubková and ****Beáta Bolerázska contributed to the analysis, All authors provide critical feedback, discussed the results and contributed to the final manuscript.

Acknowledgments: The authors express gratitude to Dr. I. Kron for his technical advice.

\section{REFERENCES}

1. Dai J, Mumper RJ. Plant phenolics: extraction, analysis and their antioxidant and anticancer properties. Molecules, 2010, 15: 7313-7352. DOI: https://doi.org/10.3390/molecules15107313

2. Procházková D, Boušová I, Wilhelmová N. Antioxidant and prooxidant properties of flavonoids. Fitoterapia, 2011, 82:513-523. DOI: https://doi.org/10.1016/j.fitote.2011.01.018

3. Scalbert A, Manach C, Morand C, Remesy C, Jimenez L. Dietary polyphenols and the prevention of diseases. Crit Rev Food Sci Nutr, 2005, 45:287-306. DOI: https://doi.org/10.1080/1040869059096

4. Foti MC. Antioxidant properties of phenols. J Pharm and Pharmacol, 2007, 59:1673-1685. DOI: https://doi.org/10.1211/jpp.59.12.0010 
5. Sahu CS, Gray GC. Kaempferol - induced nuclear DNA damage and lipid peroxidation. Cancer Lett, 1994, 85:159-164. DOI: https://doi.org/10.1016/03043835(94)90269-0

6. Gaspar J, Rodrigues A, Laires A, Silva F, Costa S, Monteiro MJ, Monteiro C, Rueff J. On the mechanics of genotoxicity and metabolism of quercetin. Mutagenesis, 1994, 9:445-449. DOI: https://doi.org/10.1093/mutage/9.5.445

7. Cao G, Sofic E, Prior RL. Antioxidant and prooxidant behavior of flavonoids:structure - activity relationships. Free Radic Biol and Med, 1994, 22:749-760. DOI: https://doi.org/10.1016/s0891-5849(96)00351-6

8. Cotelle N. Role of flavonoids in oxidative stress. Curr Top in Med Chem, 2001, 1:569-590. DOI: https://doi.org/10.2174/1568026013394750

9. Veliká B, Hubková B, Mareková M, Kron I. Využitie UV/VIS spektroskopie pre stanovení antioxidačných vlastností hydroxybenzoových kyselín pri reakcii s peroxonitritom. Chem Listy, 2015, 109:535-538.

10. D'Andrea G. Pycnogenol: A blend of procyanidins with multifacetedtherapeutic applications? Fitoterapia, 2010, 81:724-736. DOI:

https://doi.org/10.1016/j.fitote.2010.06.011

11. Petrassi C, Mastromarino A, Spartera C. Pycnogenol in chronic venous insufficiency. Phytomedicine, 2000, 7(5):383-388. DOI: https://doi.org/10.1016/s0367326x(99)00164-1

12. Kim B, Lee TK, Park CW, Kim DW, Ahn JH, Sim H, Lee JC, et al. Pycnogenol $^{\circ}$ Supplementation Attenuates Memory Deficits and Protects Hippocampal CA1 Pyramidal Neurons via Antioxidative Role in a Gerbil Model of Transient Forebrain Ischemia. Nutrients, 2020, 12(8): 2477. DOI:

https://dx.doi.org/10.3390\%2Fnu12082477

13. Lima PB, Dias JAF, Esposito ACC, Miot LDB, Miot HA French maritime pine bark extract (pycnogenol) in association with triple combination cream for the treatment of facial melasma in women: a double-blind, randomized, placebo-controlled trial. J Eur Acad Dermatol Venereol, 2021, 35(2):502-508. DOI: https://doi.org/10.1111/jdv.16896
14. Trebatická J, Duračková Z. Psychiatric Disorders and Polyphenols: Can They Be Helpful in Therapy? Oxid Med and Cell Longev, 2015, 15:16pp. DOI: https://doi.org/10.1155/2015/248529

15. Rohdewald P. A review of the French maritime pine bark extract (Pycnogenol), a herbal medication with a diverse clinical pharmacology. International J Clin Pharmacol Ther, 2002, 40(4):158-168. DOI: https://doi.org/10.5414/cpp40158

16. The American Botanical Council: Scientific and clinical monograph for Pycnogenol (French maritime pine bark extract) Pinus pinaster Aiton subsp. atlantica [Fam. Pinaceae]. 2019 Update.

17. Simpson T, Kure C, Stough C. Assessing the efficacy and mechanisms of Pycnogenol ${ }^{\circ}$ on cognitive aging from in vitro animal and human studies. Frontiers in Pharmacol, 2019, 10: 694. DOI: https://dx.doi.org/10.3389\%2Ffphar.2019.00694

18. Packer L, Rimbach G, Virgili F. Antioxidant activity and biologic properties of a procyanidin-rich extract from pine (Pinus maritima) bark, Pycnogenol. Free Radic Biol Med, 1999, 27(5-6): 704-724. DOI: https://doi.org/10.1016/s0891-5849(99)00090-8

19. Grimm T, Schäfer A, Högger P. Antioxidant activity and inhibition of matrix metalloproteinases by metabolites of maritme pine bark extract (pycnogenol). Free Radic Biol Med, 2004, 36:811-822. DOI: https://doi.org/10.1016/j.freeradbiomed.2003.12.017

20. Malekahmadi M, Moradi Moghaddam O, Islam SMS, Tanha K, Nematy M, Pahlavani N, Firouzi S, et al. Evaluation of the effects of pycnogenol (French maritime pine bark extract) supplementation on inflammatory biomarkers and nutritional and clinical status in traumatic brain injury patients in an intensive care unit: A randomized clinical trial protocol. Trials, 2020, 21(1):162. DOI: https://doi.org/10.1186/s13063019-4008-x

21. Beauchamp C, Fridovich I. Superoxide dismutase: improved assays and an assay applicable to acrylamide gels. Anal Biochem, 1971, 44:276-287. DOI: https://doi.org/10.1016/0003-2697(71)90370-8 
22. Halliwell B. Oxidative stress and neurodegeneration: where are we now? J Neurochem, 2006, 97:1634-1658. DOI: https://doi.org/10.1111/j.1471-4159.2006.03907.x

23. Pointner A, Molzer C, Magnet U, Zappe K, Hippe B, Tosevska A, Tomeva E, et al. The green tea polyphenol EGCG is differentially associated with telomeric regulation in normal human fibroblasts versus cancer cells. Functional Foods in Health and Disease, 2021, 11(3):73-91. DOI: https://doi.org/10.31989/ffhd.v11i3.775

24. Rice-Evans CA, Miller NJ, Paganga G. Structure antioxidant activity relationship of flavonoids and phenolic acids. Free Radic Biol Med, 1996, 20: 933-956. DOI: https://doi.org/10.1016/0891-5849(95)02227-9

25. Veliká B, Kron I. Antioxidant properties of benzoic acid derivatives against superoxide radical. Free Rad and Antiox, 2012, 2:62-67. DOI: https://doi.org/10.5530/ax.2012.4.11

26. Kessler M, Ubeaud G, Jung L. Anti- and pro-oxidant activity of rutin and quercetin derivatives. J Pharm and Pharmacol, 2003, 55:131-142. DOI: https://doi.org/10.1211/002235702559

27. Halliwell B. Are polyphenols antioxidants or prooxidants? What do we learn from cell culture and in vivo studies? Arch Biochem and Biophys, 2008, 476: 107112. DOI: https://doi.org/10.1016/j.abb.2008.01.028

28. Chen P, Song F, Lin LZ. Chromatographic fingerprint analysis of Pycnogenol dietary supplements. J AOAC Int. 2009, 92(2):624-32.

29. Şeker ME, Çelik A, Dost K, Erdoğan A. Investigation of Phenolic Content in Five Different Pine Barks Species Grown in Turkey by HPLC-UV and LC-MS. J Chromatogr Sci, 2021, 59(6):491-501. DOI:

https://doi.org/10.1093/chromsci/bmab022 